\title{
Reaction barrier heights for cycloreversion of heterocyclic rings: An Achilles' heel for DFT and standard ab initio procedures
}

\author{
Li-Juan Yu, ${ }^{\mathrm{a}}$ Farzaneh Sarrami, ${ }^{\mathrm{a}}$ Robert J. O'Reilly, ${ }^{\mathrm{b}}$ and Amir Karton ${ }^{\mathrm{a}, *}$

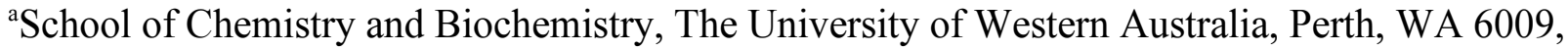 \\ Australia. \\ ${ }^{b}$ Department of Chemistry, School of Science and Technology, Nazarbayev University, Astana, \\ Republic of Kazakhstan.
}

\begin{abstract}
A B S T R A C T
We introduce a database of 20 accurate cycloreversion barrier heights of 5-membered heterocyclic rings (to be known as the $\mathrm{CRBH} 20$ database). In these reactions, dioxazole and oxathiazole rings are fragmented to form isocyanates, isothiocyanates, and carbonyls. The reference reaction barrier heights are obtained by means of the high-level, ab initio W1-F12 and $\mathrm{W} 1 \mathrm{w}$ thermochemical protocols. We evaluate the performance of 65 contemporary density functional theory (DFT) and double-hybrid DFT (DHDFT) procedures. The CRBH20 database represents an extremely challenging test for these methods. Most of the conventional DFT functionals (74\%) result in root-mean-square deviations (RMSDs) between $10-81 \mathrm{~kJ} \mathrm{~mol}^{-1}$. The rest of the DFT functionals attain RMSDs $=5-10 \mathrm{~kJ} \mathrm{~mol}^{-1}$. Of the 12 tested DHDFT functionals, only five result in RMSDs $<10 \mathrm{~kJ} \mathrm{~mol}^{-1}$. The CRBH20 dataset also proves to be a surprisingly challenging target for composite and standard ab initio procedures.
\end{abstract}

Keywords: cycloreversion $\bullet$ cycloelimination $\bullet$ density functional theory $\bullet$ G4 theory $\bullet$ W1 theory

Cite as:

L.-J. Yu, F. Sarrami, R. J. O’Reilly, A. Karton, Chem. Phys. 458, 1-8 (2015).

http://dx.doi.org/10.1016/j.chemphys.2015.07.005

Corresponding Author E-mail Address: amir.karton@uwa.edu.au (A. Karton). 


\section{Introduction}

Over the past two decades density functional theory (DFT) has become the workhorse of quantum chemical simulations due to its attractive accuracy-to-computational cost ratio relative to other electronic structure methods. However, a significant drawback of the DFT formalism is the lack of a universal DFT functional. This poses a fundamental limitation on the general applicability and intrinsic accuracy of the theory. This flaw of DFT has led to a proliferation in the number of developed DFT methods over the past two decades and in many cases also to a considerable confusion regarding which DFT method is best to use for a given chemical problem. ${ }^{1,2}$ Therefore, it is important to identify problems for which DFT methods do not perform well so that their application in similar cases would be handled with caution. At present, the only validation for a given DFT approximation is benchmarking against accurate theoretical or experimental reference data. Ideally, the benchmark data should: (i) have well-defined error bars that are much smaller (preferably, by an order of magnitude or more) than the intrinsic error of the method being evaluated, and (ii) be as large and chemically diverse as reasonably possible..$^{3,4,5,6}$

Cycloaddition reactions (or in the reverse direction, cycloreversion reactions) are one of the most important classes of organic reactions for converting simple unsaturated building blocks to cyclic structures and vice versa. Over the past decade a number of barrier heights datasets of cycloaddition reactions have been constructed for the purpose of evaluating the performance of DFT and computationally economical ab initio methods. ${ }^{6,7,9}$ It has been found that many DFT and ab initio methods perform poorly in computing the barrier heights of cycloaddition reactions. For example, a recent study ${ }^{6}$ assessed the performance of a large variety of contemporary DFT, standard ab initio, and composite ab initio methods for the set of 19 cycloaddition reactions in the GMTKN30 database. ${ }^{10}$ This set consists of highly accurate reaction barrier heights obtained by means of the Wn-F12 thermochemical protocols $(n=1$ and 2$) .{ }^{11}$ It was found that $75 \%$ of the considered DFT functionals result in root-mean-squared deviations (RMSDs) higher than $10 \mathrm{~kJ}$ mol $^{-1}{ }^{6}$ Double-hybrid DFT methods offer significantly better performance, albeit with a substantial increase in computational cost. Of the standard and modified Møller-Plesset perturbation theory (MPn) methods, MP3.5 - an average of MP3 and MP4 - gives excellent performance with an RMSD of $2.6 \mathrm{~kJ} \mathrm{~mol}^{-1}$. However, the other procedures result in RMSDs ranging from 5.8 (SCS-MP2) to 35.3 (MP2) $\mathrm{kJ} \mathrm{mol}^{-1}$. Of the composite procedures, the Gaussian4-type methods show good performance with RMSDs of 3.8 (G4) and 5.6 (G4(MP2)) kJ mol ${ }^{1}{ }^{12,13}$ On the other hand, the complete basis set (CBS) methods show surprisingly poor performance with RMSDs of over $10 \mathrm{~kJ} \mathrm{~mol}^{-1}$. $^{14,15}$ 
In the present work, we introduce a representative benchmark database of 20 reaction barrier heights of cycloreversion reactions (to be known as the CRBH20 dataset). The reference reaction barrier heights are obtained at the $\operatorname{CCSD}(\mathrm{T}) / \mathrm{CBS}$ level (i.e. coupled cluster with singles, doubles, and quasiperturbative triple excitations at the complete basis-set limit) by means of the high-level W1-F12 and W1w thermochemical protocols. ${ }^{16,17}$ These benchmark values allow us to assess the performance of more approximate theoretical procedures for the CRBH20 dataset. Specifically, we examine the performance of a variety of contemporary DFT procedures, doublehybrid DFT (DHDFT) methods, cost-effective composite thermochemistry procedures, and standard ab initio methods.

\section{Computational Methods}

In order to obtain reliable reference barrier heights for the reactions in the CRBH20 database, calculations have been carried out using the high-level, ab initio $\mathrm{W} 1 \mathrm{w}^{16,17}$ and $\mathrm{W} 1-\mathrm{F} 12^{11}$ theories with the Molpro 2012.1 program suite. ${ }^{18,19}$ These theories represent layered extrapolations to the all-electron $\operatorname{CCSD}(\mathrm{T}) / \mathrm{CBS}$ limit, ${ }^{20,21}$ and can achieve 'sub-chemical accuracy' for atomization reactions ('chemical accuracy' is arbitrarily defined here as RMSDs from accurate reference data $\leq 4.2 \mathrm{~kJ} \mathrm{~mol}^{-1}$ ). For example, $\mathrm{W} 1 \mathrm{w}$ and $\mathrm{W} 1-\mathrm{F} 12$ theories are associated with RMSDs of 2.6 and $3.1 \mathrm{~kJ} \mathrm{~mol}^{1}$ for a set of 140 very accurate atomization energies obtained at the full configuration interaction (FCI) infinite basis-set limit. ${ }^{4,11,16}$ Nevertheless, we point out that for systems containing only first-row elements (and H) W1-F12 shows better performance. Specifically, for the 97 first-row atomization energies in the W4-11 dataset, ${ }^{4} \mathrm{~W} 1-\mathrm{F} 12$ attains an RMSD of $1.9 \mathrm{~kJ} \mathrm{~mol}^{-1}$ relative to reference atomization energies at the FCI infinite basis-set limit. ${ }^{11}$ Therefore, in the present work we obtain reaction barrier heights at the W1-F12 level for systems containing only first-row elements, and with W1w for systems containing second-row elements. For the sake of making the article self-contained, we will briefly outline the various steps in W1w theory (for further details see Refs. 16 and 17). The HartreeFock (HF) component is extrapolated from the $\mathrm{A}^{\prime} \mathrm{VTZ}$ and $\mathrm{A}^{\prime} \mathrm{VQZ}$ basis sets, using the $E(L)=E_{\infty}$ $+A / L$ two-point extrapolation formula with $=5$. The notation $\mathrm{A}^{\prime} \mathrm{V} n \mathrm{Z}$ indicates the combination of the standard correlation-consistent cc-pVnZ basis sets on $\mathrm{H}_{,}{ }^{22}$ the aug-cc-pVnZ basis sets on first-row atoms, ${ }^{23}$ and the aug-cc-pV $(n+\mathrm{d}) \mathrm{Z}$ basis sets on second-row atoms. ${ }^{24}$ The valence CCSD correlation energy is extrapolated from the same basis sets with $=3.22$. The quasiperturbative triples, $(\mathrm{T})$, correction is extrapolated from the $\mathrm{A}^{\prime} \mathrm{VDZ}$ and $\mathrm{A}^{\prime} \mathrm{VTZ}$ basis sets with $=3.22$. The $\operatorname{CCSD}(\mathrm{T})$ inner-shell contribution is calculated with the MTsmall basis set, which is a completely decontracted cc-pVTZ basis set with tight 2 d1f functions added. ${ }^{16}$ W1-F12 theory is an explicitly 
correlated version of the W1w, which combines explicitly correlated F12 techniques with basisset extrapolations in order to approximate the $\operatorname{CCSD}(\mathrm{T}) / \mathrm{CBS}$ energy. The computational protocol of W1-F12 theory has been specified and rationalized in detail in Ref. 11 (for a concise summary of the various steps in W1-F12 theory see Ref. 25). The geometries of all structures have been obtained at the B3LYP/A'VTZ level of theory. ${ }^{26,27,28}$ Harmonic vibrational analyses have been performed to confirm each stationary point as an equilibrium structure (i.e., all real frequencies) or a transition structure (i.e., one imaginary frequency). All geometry optimizations and frequency calculations were performed using the Gaussian 09 program suite. ${ }^{29}$

The DFT exchange-correlation functionals considered in the present study (ordered by their rung on Jacob's Ladder) ${ }^{30}$ are the pure generalized gradient approximation (GGA) functionals: BLYP ${ }^{26,31}$ B97-D, ${ }^{32}$ HCTH407, ${ }^{33}$ PBE, ${ }^{34}$ BP86, ${ }^{31,35}$ BPW91, ${ }^{31,36}$ SOGGA11, ${ }^{37}$ N12; ${ }^{38}$ the metaGGAs (MGGAs): M06-L, ${ }^{39}$ TPSS, ${ }^{40} \tau$-HCTH, ${ }^{41}$ VSXC, ${ }^{42}$ BB95, ${ }^{43}$ M11-L, ${ }^{44}$ MN12-L; ${ }^{45}$ the hybrid-GGAs (HGGAs): BH\&HLYP, ${ }^{46}$ B3LYP,${ }^{26,27,28}$ B3P86, ${ }^{27,35}$ B3PW91, ${ }^{27,}{ }^{36}$ PBE0,${ }^{47}$ B97-1, ${ }^{48}$ B98, ${ }^{49}$ X3LYP, ${ }^{50}$ SOGGA11-X; ${ }^{51}$ the hybrid-meta-GGAs (HMGGAs): M05, ${ }^{52} \mathrm{M} 05-2 \mathrm{X},{ }^{53} \mathrm{M} 06,{ }^{54}$ M06-2X, ${ }^{54} \mathrm{M} 06-H F,{ }^{54} \mathrm{BMK},{ }^{55} \mathrm{~B} 1 \mathrm{~B} 95,{ }^{31,43} \mathrm{TPSSh}^{56} \tau$-HCTHh, ${ }^{41} \mathrm{PW} 6 \mathrm{~B} 95,{ }^{57}$ and the DHDFT procedures: ${ }^{58}$ B2-PLYP, ${ }^{59}$ B2GP-PLYP, ${ }^{60}$ B2K-PLYP, ${ }^{61}$ B2T-PLYP, ${ }^{61}$ DSD-BLYP,${ }^{62}$ DSDPBEP86, ${ }^{63,64}$ PWPB95. ${ }^{3}$ In addition to the global HGGAs and HMGGAs, we also consider the following range-separated (RS) functionals: CAM-B3LYP, ${ }^{65}$ LC- PBE, ${ }^{66}$ B97, ${ }^{67}$ B97X, ${ }^{67}$ B97X-D,${ }^{68}$ and M11. ${ }^{69}$ Empirical D3 dispersion corrections ${ }^{70,71,72}$ are included in some cases using the Becke Johnson ${ }^{73}$ damping potential as recommended in Ref. 70 (denoted by the suffix -D3). We note that the suffix -D in B97-D and B97X-D indicates the original dispersion correction rather than the D3 correction. The standard DFT calculations were carried out in conjunction with the $\mathrm{A}^{\prime} \mathrm{VTZ}$ basis set, while the DHDFT calculations, which exhibit slower basis set convergence, were carried out in conjunction with the $\mathrm{A}^{\prime} \mathrm{VQZ}$ basis set. All the DFT and DHDFT were performed using the Gaussian $09^{29}$ and $\mathrm{ORCA}^{74,75}$ program suites.

In addition, the performance of a number of composite thermochemical procedures and standard ab initio methods is assessed. We consider the following composite procedures: G4, ${ }^{12}$ G4(MP2), ${ }^{13}$ G4(MP2)-6X, ${ }^{76}$ CBS-QB3, ${ }^{14}$ CBS-APNO, ${ }^{15}$ and the following ab initio methods: MP2, SCS-MP2, ${ }^{77} \mathrm{MP} 2.5,{ }^{78} \mathrm{MP} 3, \mathrm{MP} 3.5,{ }^{6}$ SCS-MP3, ${ }^{79} \mathrm{MP} 4$, CCSD, SCS-CCSD, ${ }^{80}$ SCS(MI)CCSD, ${ }^{81}$ and CCSD(T). The performance of the MP2- and MP3-based procedures is evaluated in conjunction with the $\mathrm{A}^{\prime} \mathrm{VQZ}$ basis set whereas the performance of the computationally more expensive MP4-based and coupled cluster procedures is evaluated in conjunction with the $\mathrm{A}^{\prime} \mathrm{VTZ}$ basis set. 


\section{Results and Discussion}

3.1. Overview of the benchmark reaction barrier heights in the CRBH20 database. A schematic representation of the 20 cycloreversion reactions in the CRBH20 database is given in Figure 1, whilst the heteroatom $(\mathrm{X})$ and substituents $\left(\mathrm{R}_{1}-\mathrm{R}_{3}\right)$ are listed in Table 1. All the cycloreversion reactions involve cleavage of a heterocyclic ring into two unsaturated fragments and are the reverse of a cycloaddition reaction. In addition, these reactions involve a migration of the $\mathrm{R}_{1}$ substituent across the $\mathrm{C}=\mathrm{N}$ bond (Figure 1). There are two types of reactions in the CRBH20 dataset (Table 1):

i) Reactions 1-10 $(\mathrm{X}=\mathrm{O})$ are cycloreversions of dioxazoles to form carbonyls and isocyanates

ii) Reactions 11-20 $(\mathrm{X}=\mathrm{S})$ are cycloreversions of oxathiazoles to form carbonyls and isothiocyanates

The mechanisms of the oxathiazole ring-opening reactions have been studied both experimentally and theoretically. ${ }^{82,83,84,85,86,87}$ It has been found that the nature of the $\mathrm{R}_{1}$ and $\mathrm{R}_{2}$ substituents exerts a dramatic effect on the fragmentation barriers. Specifically, whereas diamino-substituted species elude isolation (i.e., they undergo instantaneous fragmentation at room temperature), ${ }^{84,85,86}$ dialkyl or diaryl-substituted oxathiazoles undergo fragmentation at temperatures in excess of $150{ }^{\circ} \mathrm{C} .{ }^{82,87}$ It was also found that by virtue of the fragmentation transition structures consisting of an almost product-like carbonyl moiety, the low barrier required to decompose the 5,5-diamino- vs 5,5dimethyl-substituted oxathiazole arises because the carbonyl product derived from the former (i.e., urea) is subject to substantially larger stabilizing effects than that derived from the latter (i.e., acetone).

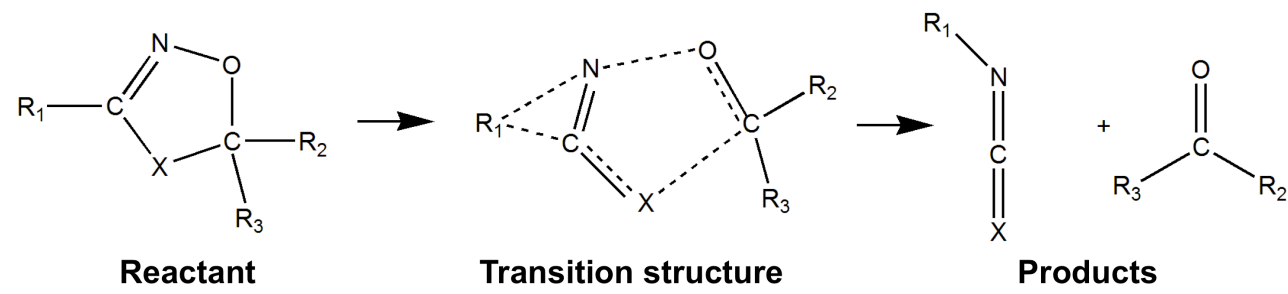

Figure 1. Schematic representation of the reactions in the CRBH20 database. The $\mathrm{X}$ center and the $\mathrm{R}_{1}-\mathrm{R}_{3}$ functional groups are listed in Table 1. 
Table 1. Cycloreversion reactions in the CRBH20 database (see also Fig. 1).

\begin{tabular}{cccccc}
\hline Reaction & $\mathbf{X}$ & $\mathbf{R}_{\mathbf{1}}$ & $\mathbf{R}_{\mathbf{2}}$ & $\mathbf{R}_{\mathbf{3}}$ \\
\hline $\mathbf{1}$ & $\mathrm{O}$ & $\mathrm{H}$ & $\mathrm{H}$ & $\mathrm{H}$ \\
$\mathbf{2}$ & $\mathrm{O}$ & $\mathrm{Me}$ & $\mathrm{H}$ & $\mathrm{H}$ \\
$\mathbf{3}$ & $\mathrm{O}$ & $\mathrm{Et}$ & $\mathrm{H}$ & $\mathrm{H}$ \\
$\mathbf{4}$ & $\mathrm{O}$ & $\mathrm{CH}_{2} \mathrm{~F}$ & $\mathrm{H}$ & $\mathrm{H}$ \\
$\mathbf{5}$ & $\mathrm{O}$ & $\mathrm{Me}$ & $\mathrm{Me}$ & $\mathrm{H}$ \\
$\mathbf{6}$ & $\mathrm{O}$ & $\mathrm{Me}$ & $\mathrm{OH}$ & $\mathrm{H}$ \\
$\mathbf{7}$ & $\mathrm{O}$ & $\mathrm{Me}$ & $\mathrm{NH}_{2}$ & $\mathrm{H}$ \\
$\mathbf{8}$ & $\mathrm{O}$ & $\mathrm{Me}$ & $\mathrm{F}$ & $\mathrm{H}$ \\
$\mathbf{9}$ & $\mathrm{O}$ & $\mathrm{Me}$ & $\mathrm{Me}$ & $\mathrm{Me}$ \\
$\mathbf{1 0}$ & $\mathrm{O}$ & $\mathrm{Me}$ & & \\
$\mathbf{1 1}$ & $\mathrm{S}$ & $\mathrm{H}$ & $\mathrm{H}$ & $\mathrm{H}$ \\
$\mathbf{1 2}$ & $\mathrm{S}$ & $\mathrm{Me}$ & $\mathrm{H}$ & $\mathrm{H}$ \\
$\mathbf{1 3}$ & $\mathrm{S}$ & $\mathrm{Et}$ & $\mathrm{H}$ & $\mathrm{H}$ \\
$\mathbf{1 4}$ & $\mathrm{S}$ & $\mathrm{CH} 2 \mathrm{~F}$ & $\mathrm{H}$ & $\mathrm{H}$ \\
$\mathbf{1 5}$ & $\mathrm{S}$ & $\mathrm{Me}$ & $\mathrm{Me}$ & $\mathrm{H}$ \\
$\mathbf{1 6}$ & $\mathrm{S}$ & $\mathrm{Me}$ & $\mathrm{OH}$ & $\mathrm{H}$ \\
$\mathbf{1 7}$ & $\mathrm{S}$ & $\mathrm{Me}$ & $\mathrm{NH}$ & $\mathrm{H}$ \\
$\mathbf{1 8}$ & $\mathrm{S}$ & $\mathrm{Me}$ & $\mathrm{F}$ & $\mathrm{H}$ \\
$\mathbf{1 9}$ & $\mathrm{S}$ & $\mathrm{Me}$ & $\mathrm{Me}$ & $\mathrm{Me}$ \\
$\mathbf{2 0}$ & $\mathrm{S}$ & $\mathrm{Me}$ & & \\
\hline
\end{tabular}

${ }^{a} \mathrm{The} \mathrm{CR}_{2} \mathrm{R}_{3}$ moiety is replaced with a $\mathrm{C}=\mathrm{O}$ group (see Figure 1 ).

The species in the CRBH20 database cover a broad spectrum of substituents and bonding situations. The $R_{1}, R_{2}$, and $R_{3}$ substituents have been selected such that: (i) the $R_{2}$ functional group is varied $\left(\mathrm{R}_{2}=\mathrm{H}, \mathrm{Me}, \mathrm{NH}_{2}, \mathrm{OH}\right.$, and $\left.\mathrm{F}\right)$, whilst maintaining a constant migrating group (i.e., $\mathrm{R}_{1}=\mathrm{Me}$ ), and (ii) the migrating group is varied $\left(\mathrm{R}_{1}=\mathrm{H}, \mathrm{Me}\right.$, Et, and $\left.\mathrm{CH}_{2} \mathrm{~F}\right)$, whilst maintaining $\mathrm{R}_{2}$ and $\mathrm{R}_{3}$ constant (i.e., $\mathrm{R}_{2}=\mathrm{R}_{3}=\mathrm{H}$ ). In addition, we consider the possibility of replacing the $\mathrm{CR}_{2} \mathrm{R}_{3}$ moiety with a $\mathrm{C}=\mathrm{O}$ group.

Benchmark reference data have been obtained by means of the high-level W1-F12 and W1w procedures. ${ }^{11,16,17}$ Since these procedures represent layered extrapolations to the CCSD(T) basis-set-limit energy, it is of interest to estimate whether the contributions from post-CCSD(T) excitations are likely to be significant. The percentage of the total atomization energy accounted for by parenthetical connected triple excitations, \% $\left.\mathrm{TAE}_{e}[\mathrm{~T})\right]$, has been shown to be a reliable energy-based diagnostic for the importance of post-CCSD(T) contributions. It has been suggested 
that $\% \mathrm{TAE}_{e}[(\mathrm{~T})]<2$ indicates systems that are dominated by dynamical correlation, while $2<$ $\% \operatorname{TAE}_{e}[(\mathrm{~T})]<5$ indicates systems that include mild nondynamical correlation. ${ }^{4,17,88}$ Table S1 (Supplementary data) gathers the \% $\left.\mathrm{TAE}_{e}[\mathrm{~T})\right]$ values for the reactants and transition structures (TSs) involved in the $\mathrm{CRBH}_{20}$ dataset. The \% $\mathrm{TAE}_{e}[(\mathrm{~T})]$ values for these species lie in the range $2.1-4.0$ (where in $78 \%$ of the cases the $\% \mathrm{TAE}_{e}[(\mathrm{~T})] \leq 3.0$ ). It is interesting to note that the reactants and TS species located along the reaction profiles are characterized by similar $\% \operatorname{TAE}_{e}[(\mathrm{~T})]$ values. For example, the average \% $\mathrm{TAE}_{e}[(\mathrm{~T})]$ values are: 2.6 (dioxazole reactants), 2.8 (oxathiazole reactants), 2.9 (dioxazole TSs), and 3.1 (oxathiazole TSs) (Table S1). These values suggest that the $\operatorname{CCSD}(\mathrm{T})$ method is adequate for the description of the reaction barrier heights in the CRBH20 database and that our bottom-of-the-well CCSD(T)/CBS benchmark values should be well below $1 \mathrm{kcal} \mathrm{mol}^{-1}$ from the full configuration interaction (FCI) basis-set limit. ${ }^{4,11,89}$

The component breakdown of the $\mathrm{W} 1-\mathrm{F} 12$ and $\mathrm{W} 1 \mathrm{w}$ reaction barrier heights are gathered in Table 2. The reaction barrier heights span a wide range from 141.1 (7) to 219.3 (14) $\mathrm{kJ}$ mol ${ }^{1}$. The lowest reaction barrier heights are obtained for $\mathrm{R}_{2}=\mathrm{NH}_{2}$, namely $\Delta E_{e}^{\ddagger}=140.1$ (dioxazole, 7) and 144.1 (oxathiazole, 17) $\mathrm{kJ} \mathrm{mol}^{-1}$. Replacing $\mathrm{R}_{2}$ with weaker donor groups $\left(\mathrm{R}_{2}=\mathrm{OH}, \mathrm{Me}\right.$, and H) systematically and significantly increases the reaction barrier heights in both the dioxazole and oxathiazole cases. Specifically, for $\mathrm{R}_{2}=\mathrm{OH}$ we obtain $\Delta E_{e^{\ddagger}}^{\ddagger} 183.0$ (dioxazole, 6) and 173.2 (oxathiazole, 16); for $\mathrm{R}_{2}=$ Me we obtain $\Delta E_{e}^{\sharp}=199.4$ (dioxazole, 5) and 204.1 (oxathiazole, 15); and for $\mathrm{R}_{2}=\mathrm{H}$ we obtain $\Delta E_{e^{\ddagger}}=213.2$ (dioxazole, 2) and 218.5 (oxathiazole, 12) $\mathrm{kJ} \mathrm{mol}^{-1}$. We also note that, with the main exception of reaction $\mathbf{8}$, the chalcogen center (X) has a relatively small effect on the reaction barrier heights. For example, for a given set of $R_{1}, R_{2}$, and $R_{3}$ substituents the difference (in absolute value) between the reaction barrier height for the dioxazole and oxathiazole rings is below $11 \mathrm{~kJ} \mathrm{~mol}^{-1}$. The only exception is reaction $\mathbf{8}$, for which this difference reaches $20.6 \mathrm{~kJ} \mathrm{~mol}^{-1}$. 
Table 2. Component breakdown of the benchmark W1-F12 and W1w reaction barrier heights for the reactions in the CRBH20 database (see Table 1 and Fig. 1 for the reaction definitions). ${ }^{a}$

\begin{tabular}{cccccc}
\hline Reaction & $\Delta$ SCF & $\Delta$ CCSD & $\Delta(\mathrm{T})$ & $\Delta \mathrm{CV}^{b}$ & $\Delta E_{e^{\ddagger c}}^{\ddagger c}$ \\
\hline $\mathbf{1}$ & 184.5 & 22.4 & -9.9 & 1.0 & 198.0 \\
$\mathbf{2}$ & 196.3 & 25.9 & -10.5 & 1.5 & 213.2 \\
$\mathbf{3}$ & 201.2 & 15.5 & -15.6 & 1.5 & 202.5 \\
$\mathbf{4}$ & 197.7 & 21.8 & -12.2 & 1.5 & 208.8 \\
$\mathbf{5}$ & 177.9 & 30.2 & -10.0 & 1.3 & 199.4 \\
$\mathbf{6}$ & 164.5 & 28.8 & -11.4 & 1.1 & 183.0 \\
$\mathbf{7}$ & 118.5 & 32.2 & -10.3 & 0.7 & 141.1 \\
$\mathbf{8}$ & 185.8 & 33.1 & -8.6 & 1.3 & 211.6 \\
$\mathbf{9}$ & 168.0 & 30.2 & -10.4 & 1.2 & 189.0 \\
$\mathbf{1 0}$ & 157.4 & 34.4 & -8.6 & 1.3 & 184.4 \\
$\mathbf{1 1}$ & 190.4 & 19.1 & -14.8 & 1.0 & 195.6 \\
$\mathbf{1 2}$ & 197.2 & 30.5 & -11.0 & 1.8 & 218.5 \\
$\mathbf{1 3}$ & 194.1 & 25.1 & -13.5 & 1.7 & 207.3 \\
$\mathbf{1 4}$ & 209.6 & 22.7 & -14.8 & 1.9 & 219.3 \\
$\mathbf{1 5}$ & 162.7 & 45.9 & -6.0 & 1.6 & 204.1 \\
$\mathbf{1 6}$ & 138.9 & 41.5 & -8.7 & 1.5 & 173.2 \\
$\mathbf{1 7}$ & 99.0 & 49.8 & -5.7 & 1.0 & 144.1 \\
$\mathbf{1 8}$ & 171.3 & 30.8 & -12.7 & 1.5 & 191.0 \\
$\mathbf{1 9}$ & 145.1 & 50.6 & -5.0 & 1.4 & 192.1 \\
$\mathbf{2 0}$ & 150.1 & 40.2 & -7.6 & 1.4 & 184.1 \\
\hline
\end{tabular}

${ }^{a}$ The reference values for reactions 1-10 are from W1-F12 theory, and for reactions 11-20 from W1w theory. ${ }^{b}$ Corevalence correction. ${ }^{c}$ All-electron, vibrationless $\operatorname{CCSD}(\mathrm{T})$ basis set limit reaction barrier heights.

In general, Hartree-Fock theory tends to overestimate reaction barrier heights since nondynamical correlation effects are usually more prominent in the TS rather than in the reactants and products..$^{90,91,92}$ Inspection of Table 2, however, reveals that the HF/CBS level of theory systematically underestimates the barrier heights in the CRBH20 database by amounts ranging from 1.3 (3) to 47.0 (19) $\mathrm{kJ} \mathrm{mol}^{-1}$ relative to the $\operatorname{CCSD}(\mathrm{T}) / \mathrm{CBS}$ reference values. A related reaction, albeit perhaps more challenging from the electronic structure point of view, where the HF/CBS level of theory underestimates the $\operatorname{CCSD}(\mathrm{T}) / \mathrm{CBS}$ barrier heights is the 1,3dipolar cycloadditions of ozone with acetylene or ethylene. ${ }^{93}$

The valence CCSD correlation contribution to the barrier heights universally increases the barrier heights by significant amounts ranging between $15.5(3)$ and $50.6(19) \mathrm{kJ} \mathrm{mol}^{-1}$. Whilst the quasiperturbative triples, $(\mathrm{T})$, contribution systematically reduces the barrier heights by amounts ranging from $5.0(19)$ and $15.6(3) \mathrm{kJ} \mathrm{mol}^{-1}$. Thus, the CCSD and (T) correlation contributions cancel each other out to some extent such that the overall $\operatorname{CCSD}(\mathrm{T})$ correlation contribution tends to increase the reaction barrier heights by amounts of up to $45.6(19) \mathrm{kJ} \mathrm{mol}^{-1}$. As mentioned, this trend is rather unusual since in general the correlation energy tends to reduce 
(rather than increase) reaction barrier heights. This reversed trend may be partially attributed to the fact that the TSs in the CRBH20 database exhibit substantial product-like character, and therefore do not have a stronger nondynamical character than the heterocyclic reactants. The product-like character of the transition structures is indicated by the $\mathrm{N} \bullet \bullet \mathrm{O}$ and $\mathrm{X} \cdot \bullet \mathrm{CR}_{2} \mathrm{R}_{3}$ bonds being largely cleaved coupled with nearly complete formation of the $\mathrm{C}=\mathrm{O}$ bond. In particular, the lengths of the $\mathrm{N} \cdots O \mathrm{O}$ bonds that are being broken in the TSs range between 1.901 (1) and 2.149 (12) $\AA$, whilst the lengths of the $X \bullet \cdot \mathrm{CR}_{2} \mathrm{R}_{3}$ bonds that are being broken range between 2.248 (10) and 3.777 (19) $\AA$. The lengths of the carbonyl $\mathrm{C}=\mathrm{O}$ bonds that are being formed in the TSs range between 1.193 (10) and 1.229 (7) A. For comparison, in the carbonyl products the lengths of these two bonds are 1.160 (10) and 1.211 (7) $\AA$ (Table S2 of the Supplementary data lists these bond lengths for all the TSs in the CRBH20 database).

3.2. Performance of DFT and DHDFT procedures. Table 3 gives the root mean square deviations (RMSDs), mean absolute deviations (MADs), and mean signed deviations (MSDs) from our benchmark W1-F12 and W1w results for a series of contemporary DFT functionals (with and without empirical D3 dispersion corrections). We start by making the following general observations:

None of the 53 conventional functionals (i.e., GGA, MGGA, HGGA, HMGGA, and RS functionals) attain RMSDs below the threshold of chemical accuracy. In particular, $26 \%$ of the functionals attain RMSDs $=5-10 \mathrm{~kJ} \mathrm{~mol}^{-1}$, and $74 \%$ of the functionals attain $\operatorname{RMSDs}=10-81 \mathrm{~kJ} \mathrm{~mol}^{-1}$.

$>$ Of the conventional functionals, the range-separated hybrid-meta GGA M11 functional of Peverati and Truhlar gives the best performance with an RMSD of $4.8 \mathrm{~kJ} \mathrm{~mol}^{-1}$. While the range-separated hybrid GGA (CAM-B3LYP-D3) and the global hybrids (SOGGA11-X and PBE0-D3) tie for second place with RMSDs of 5.6-5.8 $\mathrm{kJ} \mathrm{mol}^{-1}$.

$>$ Of the 12 considered double-hybrid functionals, only three functionals surpass the threshold of chemical accuracy. The DSD-PBEP86 functional of Kozuch and Martin attains an RMSD of merely $2.3 \mathrm{~kJ} \mathrm{~mol}^{-1}$. The superb performance of DSD-PBEP86 is followed by DSD-PBEP86-D3 and B2K-PLYP-D3, with RMSDs of 2.5 and $4.0 \mathrm{~kJ} \mathrm{~mol}^{-1}$, respectively.

Of the considered DFT and DHDFT functionals only DSD-PBEP86 and B2K-PLYP (and their dispersion corrected variants) result in largest deviations that are below $10 \mathrm{~kJ} \mathrm{~mol}^{-1}$. 
For the rest of the functionals the largest deviations span a wide range between 10.4 (PBE0-D3) and 94.0 (VSXC) $\mathrm{kJ} \mathrm{mol}^{-1}$.

With few exceptions all the conventional and double-hybrid functionals tend to systematically underestimate the reaction barrier heights, as evident from MSD $\approx-$ 1 MAD (notable exceptions include M06-HF and LC- PBE).

Dispersion corrections tend to systematically improve the agreement with the W1-F12 and $\mathrm{W} 1 \mathrm{w}$ results. Whilst for many functionals modest improvements of $\sim 1-5 \%$ in the RMSDs are observed, for BH\&HLYP, B1B95, and CAM-B3LYP the RMSDs are reduced by $12-20 \%$ upon inclusion of the D3 dispersion corrections.

Table 3. Statistical analysis for the performance of DFT and DHDFT procedures for the calculation of the reaction barrier heights in the CRBH20 database $\left.\left(\mathrm{kJ} \mathrm{mol}^{-1}\right)\right)^{a, b}$

\begin{tabular}{llcccc}
\hline Type $^{c}$ & Method & RMSD & MAD & MSD & LD $^{d}$ \\
\hline GGA & BLYP & 69.9 & 69.6 & -69.6 & $82.4(\mathbf{9})$ \\
& BLYP-D3 & 69.1 & 68.9 & -68.9 & $80.0(\mathbf{9})$ \\
& B97-D & 63.8 & 63.5 & -63.5 & $74.2(\mathbf{9})$ \\
& HCTH407 & 40.3 & 39.1 & -39.1 & $57.7(\mathbf{9})$ \\
& PBE & 32.5 & 31.9 & -31.9 & $45.2(\mathbf{9})$ \\
& PBE-D3 & 32.3 & 31.7 & -31.7 & $44.1(\mathbf{9})$ \\
& BP86 & 40.0 & 39.6 & -39.6 & $51.8(\mathbf{9})$ \\
& BP86-D3 & 39.7 & 39.3 & -39.3 & $50.0(\mathbf{9})$ \\
& BPW91 & 39.3 & 38.8 & -38.8 & $53.0(\mathbf{9})$ \\
& SOGGA11 & 13.8 & 11.0 & -10.2 & $31.2(\mathbf{7})$ \\
MGGA & N12 & 24.4 & 23.4 & -23.4 & $37.7(\mathbf{9})$ \\
& M06-L & 56.8 & 56.5 & -56.5 & $66.0(\mathbf{9})$ \\
& TPSS & 41.7 & 41.4 & -41.4 & $50.1(\mathbf{9})$ \\
& TPSS-D3 & 41.4 & 41.2 & -41.2 & $48.7(\mathbf{9})$ \\
& T-HCTH & 41.7 & 41.0 & -41.0 & $57.7(\mathbf{9})$ \\
& VSXC & 81.1 & 80.6 & -80.6 & $94.0(\mathbf{9})$ \\
& BB95 & 49.9 & 49.5 & -49.5 & $63.0(\mathbf{9})$ \\
& M11-L & 39.9 & 39.6 & -39.6 & $50.6(\mathbf{1 1})$ \\
& MN12-L & 28.1 & 26.9 & -26.9 & $42.1(\mathbf{1 7})$ \\
HGGA & BH\&HLYP & 9.0 & 6.8 & -5.7 & $21.3(\mathbf{1 9})$ \\
& BH\&HLYP-D3 & 7.2 & 5.9 & -5.0 & $14.6(\mathbf{1 7})$ \\
& B3LYP & 35.0 & 34.6 & -34.6 & $47.1(\mathbf{1 9})$ \\
& B3LYP-D3 & 34.2 & 34.0 & -34.0 & $41.7(\mathbf{9})$ \\
& B3P86 & 7.3 & 6.1 & -6.1 & $14.6(\mathbf{9})$ \\
& B3PW91 & 10.9 & 9.8 & -9.8 & $20.0(\mathbf{9})$ \\
& B3PW91-D3 & 10.1 & 9.4 & -9.4 & $18.1(\mathbf{9})$ \\
& PBE0 & 6.2 & 5.5 & 4.6 & $10.9(\mathbf{1 2})$ \\
& PBE0-D3 & 5.8 & 5.2 & 4.7 & $10.4(\mathbf{1 2})$ \\
& B97-1 & 22.4 & 21.8 & -21.8 & $31.8(\mathbf{9})$ \\
& B98 & 22.9 & 22.4 & -22.4 & $33.7(\mathbf{1 9})$
\end{tabular}




\begin{tabular}{|c|c|c|c|c|c|}
\hline & X3LYP & 31.5 & 31.1 & -31.1 & 43.3 (19) \\
\hline & SOGGA11-X & 5.6 & 4.8 & 1.9 & $10.7(\mathbf{1 1})$ \\
\hline \multirow[t]{13}{*}{ HMGGA } & M05 & 32.1 & 31.4 & -31.4 & 44.4 (19) \\
\hline & M05-2X & 13.2 & 12.5 & 12.5 & $19.7(\mathbf{1})$ \\
\hline & M06 & 35.5 & 35.4 & -35.4 & 40.6 (19) \\
\hline & M06-2X & 6.8 & 5.7 & 3.9 & $12.3(3)$ \\
\hline & M06-HF & 43.6 & 42.1 & 42.1 & $63.0(1)$ \\
\hline & $\mathrm{BMK}$ & 12.9 & 11.3 & -11.3 & $24.2(\mathbf{1 7})$ \\
\hline & BMK-D3 & 11.9 & 11.0 & -11.0 & $20.5(17)$ \\
\hline & B1B95 & 8.8 & 7.6 & -7.6 & 16.9 (19) \\
\hline & B1B95-D3 & 7.7 & 7.0 & -7.0 & $14.2(9)$ \\
\hline & TPSSh & 26.4 & 26.1 & -26.1 & 35.2 (19) \\
\hline & $\tau$-HCTHh & 26.5 & 26.1 & -26.1 & $35.5(9)$ \\
\hline & PW6B95 & 16.7 & 16.0 & -16.0 & 25.7 (19) \\
\hline & PW6B95-D3 & 16.5 & 16.0 & -16.0 & $23.6(\mathbf{1 9})$ \\
\hline \multirow[t]{8}{*}{ RS } & CAM-B3LYP & 6.5 & 5.0 & -3.9 & 16.2 (19) \\
\hline & CAM-B3LYP-D3 & 5.7 & 4.5 & -3.9 & $13.1(\mathbf{1 9})$ \\
\hline & LC- PBE & 39.5 & 39.0 & 39.0 & $50.1(\mathbf{1 4})$ \\
\hline & LC- PBE-D3 & 39.6 & 39.1 & 39.1 & $49.4(14)$ \\
\hline & B97 & 13.3 & 11.4 & 11.4 & 23.7 (11) \\
\hline & B97X & 7.3 & 5.6 & 4.4 & 14.7 (11) \\
\hline & B97X-D & 6.7 & 5.2 & -4.4 & 14.7 (19) \\
\hline & M11 & 4.8 & 3.9 & 0.1 & $10.6(\mathbf{1 7})$ \\
\hline \multirow[t]{12}{*}{$\mathrm{DH}$} & B2-PLYP & 23.1 & 22.9 & -22.9 & $29.0(7)$ \\
\hline & B2-PLYP-D3 & 22.6 & 22.5 & -22.5 & $28.0(7)$ \\
\hline & B2GP-PLYP & 10.8 & 10.5 & -10.5 & $16.0(7)$ \\
\hline & B2GP-PLYP-D3 & 10.2 & 10.0 & -10.0 & $15.5(7)$ \\
\hline & B2K-PLYP & 4.3 & 3.6 & -3.3 & $8.5(7)$ \\
\hline & B2K-PLYP-D3 & 4.0 & 3.5 & -3.2 & $8.6(7)$ \\
\hline & B2T-PLYP & 15.3 & 15.0 & -15.0 & $20.7(7)$ \\
\hline & DSD-BLYP & 7.4 & 7.0 & -7.0 & $12.6(7)$ \\
\hline & DSD-PBEP86 & 2.3 & 1.8 & 0.1 & $5.1(11)$ \\
\hline & DSD-PBEP86-D3 & 2.5 & 2.0 & 0.9 & $5.8(11)$ \\
\hline & PWPB95 & 10.4 & 10.0 & -10.0 & $15.2(7)$ \\
\hline & PWPB95-D3 & 10.2 & 9.9 & -9.9 & $14.9(7)$ \\
\hline
\end{tabular}

${ }^{a}$ The standard DFT calculations are carried out in conjunction with the $\mathrm{A}^{\prime} \mathrm{VTZ}$ basis set while the DHDFT calculations are carried out in conjunction with the $\mathrm{A}^{\prime} \mathrm{VQZ}$ basis set. ${ }^{b} \mathrm{RMSD}=$ root mean square deviation, $\mathrm{MAD}=$ mean absolute deviation, $\mathrm{MSD}=$ mean signed deviation, $\mathrm{LD}=$ largest deviation (in absolute value). ${ }^{c} \mathrm{GGA}=$ generalized gradient approximation, HGGA = hybrid-GGA, MGGA = meta-GGA, RS = range-separated, HMGGA $=$ hybrid-meta-GGA, $\mathrm{DH}=$ double hybrid. ${ }^{d}$ The reaction numbers are given in parenthesis (see also Table 1 and Fig. 1).

The eleven considered GGA functionals show very poor performance. With the exception of SOGGA11, the GGA functionals result in RMSDs between 24.4 (N12) and 69.9 (BLYP) kJ mol ${ }^{-1}$. The SOGGA11 functional attains an RMSD of $13.8 \mathrm{~kJ} \mathrm{~mol}^{-1}$ and is clearly superior to the other GGAs.

Inclusion of the kinetic energy density in the MGGA procedures does not improve the performance. In fact, none of the considered MGGA functionals attains an RMSD below $28 \mathrm{~kJ}$ 
$\mathrm{mol}^{-1}$. All the GGA and MGGA functionals significantly underestimate the reaction barrier heights as evident from MSD $\approx-1$ MAD. These results suggest that GGA and MGGA functionals should be applied with caution when calculating barrier heights for cycloreversion reactions. We note that reaction 9 seems to be particularly problematic for most of the GGA and MGGA procedures. For example, for 16 of the 19 considered functionals the largest deviation (of 37.7-94.0 $\mathrm{kJ} \mathrm{mol}^{-1}$, Table 3) is obtained for reaction 9.

The HGGAs show better performance than the GGAs and MGGAs. For example, eight out of the 13 considered hybrid GGAs result in RMSDs $<11.0 \mathrm{~kJ} \mathrm{~mol}^{-1}$. We note that both B3LYP and X3LYP show very poor performance with RMSDs of over $30.0 \mathrm{~kJ} \mathrm{~mol}^{-1}$. It is instructive to compare the performance of the three hybrid functionals B3P86, B3PW91, and B3LYP, which combine Becke's three-parameter exchange functional with different gradient-corrected correlation functionals. These functionals give RMSDs of 7.3, 10.9, and $35.0 \mathrm{~kJ} \mathrm{~mol}{ }^{-1}$, respectively. Thus, B3P86 and B3PW91 are clearly superior to the B3LYP functional, having significantly smaller RMSDs. The best HGGA functionals are (RMSDs are given in parenthesis): SOGGA11-X (5.6), PBE0-D3 (5.8), PBE0 (6.2), BH\&HLYP-D3 (7.2), and B3P86 (7.3 kJ mol ${ }^{-1}$ ).

Ten out of the 13 HMGGA functionals result in RMSDs ranging between 11.9 (BMK-D3) and $43.6(\mathrm{M} 06-\mathrm{HF}) \mathrm{kJ} \mathrm{mol}^{-1}$. The RMSDs of the other three HMGGAs are: 6.8 (M06-2X), 7.7 (B1B95-D3), and 8.8 (B1B95) $\mathrm{kJ} \mathrm{mol}^{-1}$. As expected, the percentage of HF-like exchange plays an important role for the reaction barrier heights. For example, the RMSDs are dramatically reduced from 69.9 (BLYP, pure GGA) to 9.0 (BH\&HLYP, 50\% HF-like exchange) kJ mol ${ }^{-1}$. For the M06 family of functionals we obtain the following RMSDs: 56.8 (M06-L, pure MGGA), 35.5 (M06, 27\% HF-like exchange), and 6.8 (M06-2X, 54\% HF-like exchange) kJ mol ${ }^{-1}$. Similarly, for the pure GGA PBE and the HGGA PBE0 (with 25\% HF-like exchange) we obtain RMSDs of 32.5 and $6.2 \mathrm{~kJ} \mathrm{~mol}^{-1}$, respectively. Nevertheless, inspection of Table 2 reveals that the optimal percentage of HF-like exchange spans over a wide range of $20-55 \%$. The best performing functionals with 20-28\% of HF-like exchange are: B3P86 (7.3), PBE0-D3 (5.8), PBE0 (6.2), and B1B95-D3 $\left(7.7 \mathrm{~kJ} \mathrm{~mol}^{-1}\right)$. At the other end, functionals with $40-55 \%$ of HF-like exchange that perform well are: SOGGA11-X (5.6), BH\&HLYP-D3 (7.2), and M06-2X (6.8 kJ mol $\left.{ }^{-1}\right)$.

With the exception of LC- PBE, the range-separated hybrid- and hybrid-meta-GGAs give good performance with RMSDs ranging between 4.8 (M11) and 13.3 ( B97) kJ mol${ }^{-1}$. The good performance of M11 is followed by CAM-B3LYP-D3 (RMSD = 5.7) and B97X-D (RMSD = $\left.6.7 \mathrm{~kJ} \mathrm{~mol}^{-1}\right)$.

The CRBH20 dataset proves to be a challenging dataset also for most of the considered double-hybrid functionals. For example, both B2GP-PLYP-D3 and PWPB95-D3 result in an 
RMSD of $10.2 \mathrm{~kJ} \mathrm{~mol}^{-1}$. The older-generation double-hybrids B2T-PLYP and B2-PLYP-D3 result in RMSDs of 15.3 and $22.6 \mathrm{~kJ} \mathrm{~mol}^{-1}$, respectively. The B2K-PLYP-D3 functional, which was parameterized for thermochemical kinetics, shows good performance with an RMSD of 4.0 $\mathrm{kJ} \mathrm{mol}^{-1}$ (just below the threshold of chemical accuracy). The recently developed spincomponent-scaled double-hybrid DSD-PBEP86, however, shows exceptional performance with an RMSD of merely $2.3 \mathrm{~kJ} \mathrm{~mol}^{-1}$, a near-zero MSD of $+0.1 \mathrm{~kJ} \mathrm{~mol}^{-1}$, and a largest deviation which is just above the chemical accuracy threshold.

Due to the high computational cost of the DHDFT methods in conjunction with the A'VQZ basis set, it is also of interest to evaluate the performance of these procedures using smaller basis sets. Table 4 gives an overview of the basis-set convergence for the DHDFT procedures. The tabulated values are the differences between the RMSDs obtained with A'VQZ basis set (reported in Table 3 ) and those obtained with the smaller $\mathrm{A}^{\prime} \mathrm{V} n \mathrm{Z}$ basis sets $(n=\mathrm{D}$ and T), i.e., $\mathrm{RMSD}=$ $\operatorname{RMSD}\left(\mathrm{A}^{\prime} \mathrm{V} n \mathrm{Z}\right) \quad \mathrm{RMSD}\left(\mathrm{A}^{\prime} \mathrm{VQZ}\right)$. A positive $\mathrm{RMSD}$ value indicates that the use of the smaller basis set results in an overall deterioration in the performance, whereas a negative RMSD value indicates an improvement in performance with the smaller basis set. Inspection of Table 4 reveals that the use of the $\mathrm{A}^{\prime} \mathrm{VTZ}$ basis set results in very small performance deteriorations. In particular, the RMSDs are increased by amounts ranging from 0.2 (PWPB95) and 0.7 (DSD-BLYP) kJ mol ${ }^{1}$ upon going from the $\mathrm{A}^{\prime} \mathrm{VQZ}$ to the $\mathrm{A}^{\prime} \mathrm{VTZ}$ basis set (with the exception of DSD-PBEP86 for which the performance with the $\mathrm{A}^{\prime} \mathrm{VTZ}$ basis set is improved by $0.4 \mathrm{~kJ} \mathrm{~mol}^{-1}$ ). Interestingly, for the problem at hand, even the A'VDZ basis set gives rather useful results. Namely, the RMSDs with the $A^{\prime} V D Z$ basis set are higher than those with the $A^{\prime} V Q Z$ basis set by amounts ranging from 0.5 (DSD-PBEP86) to 2.0 (DSD-BLYP) $\mathrm{kJ} \mathrm{mol}^{-1}$. We note, however, that the RMSD for the PWPB95 functional decreases by $3.6 \mathrm{~kJ} \mathrm{~mol}^{-1}$ when going from the $\mathrm{A}^{\prime} \mathrm{VQZ}$ to the $\mathrm{A}^{\prime} \mathrm{VDZ}$ basis set. For the sake of completeness, Table S4 of the Supplementary data gives an overview of the basis set convergence for the conventional DFT methods. The A'VTZ basis set yields very good performance with results that are near the basis set limit. In particular, the RMSD(A'VTZ) RMSD(A'VQZ) differences (in absolute value) are smaller than $1 \mathrm{~kJ} \mathrm{~mol}^{-1}$ in practically all cases. 
Table 4. Overview of the basis set convergence of the DHDFT methods. The tabulated values are $\Delta \operatorname{RMSD}\left(\mathrm{A}^{\prime} \mathrm{V} n \mathrm{Z}\right)=\operatorname{RMSD}\left(\mathrm{A}^{\prime} \mathrm{V} n \mathrm{Z}\right) \quad \mathrm{RMSD}\left(\mathrm{A}^{\prime} \mathrm{VQZ}\right)\left(\right.$ in $\left.\mathrm{kJ} \mathrm{mol}^{-1}\right){ }^{a}$

\begin{tabular}{lcc}
\hline Method & $\begin{array}{c}\Delta \text { RMSD } \\
\text { (A'VTZ) }\end{array}$ & $\begin{array}{c}\Delta \text { RMSD } \\
\left(\mathrm{A}^{\prime} \mathrm{VDZ}\right)\end{array}$ \\
\hline B2-PLYP & 0.6 & -1.1 \\
B2GP-PLYP & 0.6 & 0.8 \\
B2K-PLYP & 0.4 & 1.5 \\
B2T-PLYP & 0.6 & -0.1 \\
DSD-BLYP & 0.7 & 2.0 \\
DSD-PBEP86 & -0.4 & 0.5 \\
PWPB95 & 0.2 & -3.6 \\
\hline
\end{tabular}

${ }^{a}$ A positive RMSD value indicates that the smaller basis set results in an overall deterioration in the performance, whereas a negative value indicates an improvement in performance with the smaller basis set.

Finally, it is worthwhile looking at the performance of the DFT and DHDFT methods for the reaction barrier heights in the reverse direction (i.e., for the cycloaddition reactions). Table S3 of the Supplementary data gathers the error statistics for these methods. Generally speaking, the performance is considerably improved for functionls from rungs two and three of Jacob's Ladder, with RMSDs ranging between 4.7 (M11-L) and 36.2 (BP86-D3) $\mathrm{kJ} \mathrm{mol}^{-1}$. However, for the higher rung RS and DHDFT functionals the performance for the cycloaddition reactions tends to deteriorate relative to the performance for the cycloreversion reactions.

3.3. Performance of standard and composite ab initio procedures. Table 5 gives an overview of the performance of the composite G3, G3(MP2), G4, G4(MP2), G4(MP2)-6X, CBS-QB3, and CBS-APNO procedures, as well as several ab initio methods (e.g., MP2, MP2.5, MP3, MP3.5, MP4, SCS-MP2, SCS-MP3, CCSD and CCSD(T)). Upon inspection of the results for the composite procedures, a few interesting features emerge. None of the $\mathrm{G} n$-type procedures result in RMSDs below the chemical accuracy threshold. The G3-type procedures exhibit relatively poor performance with RMSDs ranging between 6.4 (G3) and 12.6 (G3(MP2)B3) kJ mol ${ }^{-1}$. Interestingly, the G3 and G3(MP2) procedures give significantly better performance than G3B3 and G3(MP2)B3, respectively. However, there seems to be no merit in using the G3-type procedures over the more recent G4-type procedures, since the latter have a similar computational cost and give better performance (Table 5). Of the G4-type procedures, G4(MP2)6X, which has the same computational cost as G4(MP2) gives the best performance with an RMSD of $4.9 \mathrm{~kJ} \mathrm{~mol}^{-1}$. The G4 procedure gives a slightly larger RMSD of $5.1 \mathrm{~kJ} \mathrm{~mol}^{-1}$, whilst $\mathrm{G} 4(\mathrm{MP} 2)$ results in an RMSD of $6.6 \mathrm{~kJ} \mathrm{~mol}^{-1}$. 
Table 5. Statistical analysis for the performance of composite and standard ab initio methods for the calculation of the reaction barrier heights in the $\mathrm{CRBH} 20$ database (in $\mathrm{kJ} \mathrm{mol}^{-1}$ ). ${ }^{a}$

\begin{tabular}{|c|c|c|c|c|c|}
\hline Basis set & Methods & RMSD & MAD & MSD & LD \\
\hline & G3 & 6.4 & 5.3 & -4.9 & $10.3(\mathbf{1 3})$ \\
\hline & G3(MP2) & 7.3 & 6.0 & -5.9 & $11.7(\mathbf{1 4})$ \\
\hline & G3B3 & 11.2 & 10.7 & -10.7 & $17.0(\mathbf{1 1})$ \\
\hline & G3(MP2)B3 & 12.6 & 12.0 & -12.0 & 19.5 (11) \\
\hline & G4 & 5.1 & 4.6 & -4.6 & 7.7 (12) \\
\hline & G4(MP2) & 6.6 & 6.1 & -6.1 & 9.9 (12) \\
\hline & G4(MP2)-6X & 4.9 & 4.2 & -4.2 & $8.4(12)$ \\
\hline & CBS-QB3 & 3.1 & 2.5 & -2.1 & $6.1(13)$ \\
\hline & CBS-APNO $^{b}$ & 1.5 & 0.5 & 0.1 & $3.0(3)$ \\
\hline \multirow[t]{6}{*}{$\mathrm{A}^{\prime} \mathrm{VQZ}$} & $\mathrm{HF}$ & 25.6 & 22.5 & -22.5 & 46.9 (19) \\
\hline & MP2 & 23.7 & 23.4 & 23.4 & 31.6 (19) \\
\hline & SCS-MP2 & 17.2 & 16.8 & 16.8 & $27.5(11)$ \\
\hline & MP2.5 & 26.4 & 26.3 & 26.3 & 34.4 (11) \\
\hline & MP3 & 29.5 & 29.1 & 29.1 & 38.4 (3) \\
\hline & SCS-MP3 & 17.8 & 17.4 & 17.4 & $28.2(\mathbf{1 1})$ \\
\hline \multirow[t]{9}{*}{$\mathrm{A}^{\prime} \mathrm{VTZ}$} & MP3.5 & 11.3 & 11.0 & 11.0 & $16.5(11)$ \\
\hline & MP4(SDQ) & 5.7 & 4.9 & 4.9 & 10.9 (11) \\
\hline & MP4(SDTQ) & 6.1 & 5.6 & -5.6 & $9.4(\mathbf{1 0})$ \\
\hline & $\mathrm{MP}_{\mathrm{av}}$ & 2.1 & 1.7 & -0.3 & 4.7 (11) \\
\hline & CCSD & 6.3 & 5.8 & 5.8 & $10.6(3)$ \\
\hline & SCS-CCSD & 12.2 & 12.1 & 12.1 & $14.7(7)$ \\
\hline & SCS(MI)CCSD & 10.5 & 10.4 & 10.4 & $12.8(8)$ \\
\hline & $\operatorname{CCSD}(\mathrm{T})$ & 5.0 & 4.8 & -4.8 & $6.9(12)$ \\
\hline & $\operatorname{CCSD}(\mathrm{T}) / \mathrm{CBS}(\mathrm{MP} 2)^{c}$ & 1.7 & 1.5 & -1.0 & $2.6(4)$ \\
\hline
\end{tabular}

${ }^{a}$ Footnote $b$ to Table 3 applies here. ${ }^{b}$ Error statistics over the dioxazoles systems only. ${ }^{c} \mathrm{CCSD}(\mathrm{T}) / \mathrm{CBS}(\mathrm{MP} 2) \approx$ $\operatorname{CCSD}(\mathrm{T}) / \mathrm{A}^{\prime} \mathrm{VDZ}+\mathrm{MP} 2 / \mathrm{A}^{\prime} \mathrm{V}\{\mathrm{T}, \mathrm{Q}\} \mathrm{Z}-\mathrm{MP} 2 / \mathrm{A}^{\prime} \mathrm{VDZ}$.

The CBS-type procedures show better performance than the Gn-type procedures with RMSDs below the threshold of chemical accuracy. In particular, we obtain RMSDs of 3.1 (CBSQB3) and 1.5 (CBS-APNO) $\mathrm{kJ} \mathrm{mol}^{-1}$. The CBS-APNO method outperforms all of the considered DFT and standard/composite ab initio methods, and is also one of the few methods that are associated with a largest deviation below the threshold of chemical accuracy (namely, $3.0 \mathrm{~kJ} \mathrm{~mol}^{-}$ ${ }^{1}$, Table 5).

However, the performance trends of the $\mathrm{G} n$ - and CBS-type composite methods are the reverse of those obtained for the set of 26 barrier heights of pericyclic reactions. ${ }^{6}$ For the pericyclic reactions the G4-type procedures give good performance with RMSDs between 3.3 (G4) and 5.4 (G4(MP2)) $\mathrm{kJ} \mathrm{mol}^{-1}$, whist the CBS-type procedures result in RMSDs $\geq 10.0 \mathrm{~kJ}$ $\mathrm{mol}^{-1}$. This illustrates the importance of benchmarking the performance of empirical composite procedures for specific reaction types and systems prior to applying them for the calculation of 
reaction barrier heights. Finally, we note that all the composite procedures tend to systematically underestimate the reaction barrier heights. This is consistent with the performance of these composite methods for the barrier heights of pericyclic reactions. ${ }^{6}$

We now turn our attention to the performance of the standard wavefunction methods. Table 5 gives these results in conjunction with the $\mathrm{A}^{\prime} \mathrm{VQZ}$ for the computationally economical MP2- and MP3-based methods, whilst the performance of the MP4-based and coupled cluster methods is evaluated in conjunction with the A'VTZ basis set. Table S5 of the Supplementary data gives results for all the standard ab initio methods in conjunction with the $\mathrm{A}^{\prime} \mathrm{V} n \mathrm{Z}$ basis sets ( $n=\mathrm{D}$ and $\mathrm{T}$ ). We start by noting that for the methods for which we have both $\mathrm{A}^{\prime} \mathrm{VTZ}$ and $\mathrm{A}^{\prime} \mathrm{VQZ}$ results (HF, MP2, SCS-MP2, MP2.5, MP3, and SCS-MP3) the difference in the overall RMSDs between the $\mathrm{A}^{\prime} \mathrm{VTZ}$ and $\mathrm{A}^{\prime} \mathrm{VQZ}$ basis sets are smaller than $1.7 \mathrm{~kJ} \mathrm{~mol}^{-1}$. However, the difference in the RMSDs between the $\mathrm{A}^{\prime} \mathrm{VDZ}$ and $\mathrm{A}^{\prime} \mathrm{VTZ}$ are much larger: namely (in absolute value) they range between $2.0(\mathrm{MP} 4(\mathrm{SDQ}))$ and 9.1 (MP2) $\mathrm{kJ} \mathrm{mol}^{-1}$. We also note that for all of the MP2- and MP3-based methods the A'VDZ basis set performs significantly better than the A'VTZ (relative to the $\mathrm{W} 1-\mathrm{F} 12$ and $\mathrm{W} 1 \mathrm{w}$ reference values). This results from an error compensation between basis set incompleteness and the neglect of higher-level correlation effects.

Inspection of Table 5 reveals that the CRBH20 database is a challenging test for nearly all of the standard $a b$ initio methods. Only two of the 15 examined procedures result in RMSDs below the chemical accuracy threshold. For the other 13 methods the RMSDs range between 5.0 $\left(\mathrm{CCSD}(\mathrm{T}) / \mathrm{A}^{\prime} \mathrm{VTZ}\right)$ and 29.5 (MP3/A'VQZ) $\mathrm{kJ} \mathrm{mol}^{-1}$. As mentioned in Section 3.1, HF theory systematically and severely underestimates the W1-F12 and W1w reaction barrier heights. For the HF/A'VQZ level of theory we obtain an RMSD of $25.6 \mathrm{~kJ} \mathrm{~mol}^{-1}$ and an MSD $=-1$ MAD $=-$ $22.5 \mathrm{~kJ} \mathrm{~mol}^{-1}$ (we note that these values remain essentially unchanged for the HF/CBS level of theory from W1-F12 and W1w theories).

Second-order Møller-Plesset perturbation theory (MP2) systematically overestimates the reaction barrier heights and results in an $\mathrm{RMSD}$ of $23.7 \mathrm{~kJ} \mathrm{~mol}^{-1}$ and an $\mathrm{MSD}=\mathrm{MAD}=+23.4 \mathrm{~kJ}$ $\mathrm{mol}^{-1}$. Scaling the same-spin and opposite-spin components of the MP2 correlation energy, as in the SCS-MP2 procedure, improves the situation to some extent, but still leads to an unacceptably large RMSD of $17.2 \mathrm{~kJ} \mathrm{~mol}^{-1}$ and an $\mathrm{MSD}=\mathrm{MAD}=+16.8 \mathrm{~kJ} \mathrm{~mol}^{-1}$. Inclusion of higher-order excitations in procedures such as MP2.5, MP3, and SCS-MP3, results in even worse performance than the MP2 and SCS-MP2 procedures (Table 5). Where in all cases the reaction barrier heights are severely overestimated.

Full forth-order Møller-Plesset perturbation theory (MP4(SDTQ)) provides a significant improvement over MP2 and MP3, with an RMSD of $6.1 \mathrm{~kJ} \mathrm{~mol}^{-1}$. We note that this is also the 
only MP $n$ method that systematically underestimates the reaction barrier heights, with MSD = $1 \mathrm{MAD}=-5.6 \mathrm{~kJ} \mathrm{~mol}^{-1}$. Partial fourth-order Møller-Plesset perturbation theory (MP4(SDQ)) provides similar performance with an RMSD of $5.7 \mathrm{~kJ} \mathrm{~mol}^{-1}$. However, in contrast to MP4(SDTQ), MP4(SDQ) systematically overestimates the reaction barrier heights, with an MSD $=\mathrm{MAD}=+4.9 \mathrm{~kJ} \mathrm{~mol}^{-1}$. In this situation, it is useful to define a new method as the average of MP4(SDTQ) and MP4 (SDQ). This method is denoted here by MP4av. For the reaction barrier heights in the CRBH20 database the MP4av method results in an exceptionally low RMSD of 2.1 $\mathrm{kJ} \mathrm{mol}^{-1}$. In fact, this method significantly outperforms the computationally more expensive $\operatorname{CCSD}(\mathrm{T}) / \mathrm{A}^{\prime} \mathrm{VTZ}$ level of theory as well as all of the considered DHDFT and MP $n$-based procedures. The excellent performance of $\mathrm{MP}_{\mathrm{av}}$ is also demonstrated by a near-zero MSD of $0.3 \mathrm{~kJ} \mathrm{~mol}^{-1}$, suggesting that it is free of systematic bias. We also note that $\mathrm{MP}_{\mathrm{av}}$ performs exceptionally well for the 26 barrier heights of pericyclic reactions in the GMTKN30 database. ${ }^{6}$ For example, the MP4av/A'VTZ level of theory results in an RMSD of $2.5 \mathrm{~kJ} \mathrm{~mol}^{-1}$ and an MSD of $-0.4 \mathrm{~kJ} \mathrm{~mol}^{-1}$ for this subset.

The CCSD/A'VTZ level of theory shows poor performance with an RMSD of $6.3 \mathrm{~kJ} \mathrm{~mol}^{-}$ 1. It should be noted, however, that at the CCSD/CBS level of theory (taken from W1-F12 and W1w theories) this RMSD increases to $9.5 \mathrm{~kJ} \mathrm{~mol}^{-1}$. Thus, the CCSD/A'VTZ level of theory benefits from some error compensation between basis set incompleteness and the neglect of the quasiperturbative triples, (T), corrections.

The CCSD(T) method attains RMSDs of 13.9 and $5.0 \mathrm{~kJ} \mathrm{~mol}^{-1}$ in conjunction with the $\mathrm{A}^{\prime} \mathrm{VDZ}$ and $\mathrm{A}^{\prime} \mathrm{VTZ}$ basis sets, respectively. It is of interest to assess the performance of the $\operatorname{CCSD}(\mathrm{T})$ method using an additivity-based approach in which the $\operatorname{CCSD}(\mathrm{T}) / \mathrm{CBS}$ energy is estimated from the CCSD(T)/A'VDZ energy and an MP2-based basis-set-correction term $(\triangle \mathrm{MP} 2$ $=\mathrm{MP} 2 / \mathrm{A}^{\prime} \mathrm{V}\{\mathrm{T}, \mathrm{Q}\} \mathrm{Z}-\mathrm{MP} 2 / \mathrm{A}^{\prime} \mathrm{VDZ}$, where the MP2/A'V $\{\mathrm{T}, \mathrm{Q}\} \mathrm{Z}$ energy is extrapolated to the basis-set limit with an extrapolation exponent of 3). ${ }^{94}$ This cost-effective approach, which is denoted here by $\operatorname{CCSD}(\mathrm{T}) / \mathrm{CBS}(\mathrm{MP} 2)$, has been widely used for obtaining noncovalent interaction energies at the CCSD(T)/CBS limit. ${ }^{5,95,96,97,98}$ More recently, this method has also been found to give good performance for reaction energies ${ }^{99,100,101}$ and barrier heights. ${ }^{6}$ For the reaction barrier heights in the $\mathrm{CRBH} 20$ database the $\mathrm{CCSD}(\mathrm{T}) / \mathrm{MP} 2(\mathrm{CBS})$ method gives excellent performance with an RMSD and MSD of 1.7 and $-1.0 \mathrm{~kJ} \mathrm{~mol}^{-1}$, respectively. Note also that this method is associated with a largest deviation well below the threshold of chemical accuracy (i.e., $2.6 \mathrm{~kJ} \mathrm{~mol}^{-1}$, Table 5). 


\section{Conclusions}

We have obtained benchmark reaction barrier heights by means of the high-level W1-F12 and $\mathrm{W} 1 \mathrm{w}$ composite thermochemistry protocols for a diverse set of cycloreversion reactions involving the fragmentation of 5-membered heterocyclic rings. We use these benchmark reaction barrier heights (a.k.a. the $\mathrm{CRBH} 20$ database) to evaluate the performance of a variety of contemporary density functional theory and ab initio procedures. With regard to the performance of the DFT and DHDFT procedures we make the following observations:

$>$ The CRBH20 dataset proves to be an extremely challenging test for all of the conventional DFT procedures.

$>$ With no exceptions, all the conventional DFT methods (rungs 1-4 of Jacob's Ladder) result in RMSDs above the chemical accuracy threshold, and 74\% of the tested functionals give very poor performance with RMSDs $=10-81 \mathrm{~kJ} \mathrm{~mol}^{-1}$.

$>$ The range-separated hybrid-meta GGA M11 emerges as the best performing conventional DFT functional, with RMSD $=4.8 \mathrm{~kJ} \mathrm{~mol}^{-1}$.

$>$ Of the DHDFT functionals, DSD-PBEP86, DSD-PBEP86-D3, and B2K-PLYP-D3 are the only functionals that surpass the chemical accuracy threshold (with RMSD $=2.3,2.5$, and $4.0 \mathrm{~kJ} \mathrm{~mol}^{-1}$, respectively). The rest of the DHDFTs give relatively poor performance with RMSDs $>10 \mathrm{~kJ} \mathrm{~mol}^{-1}$ (with the exception of DSD-BLYP, for which RMSD $=7.4 \mathrm{~kJ} \mathrm{~mol}^{-}$ $\left.{ }^{1}\right)$.

With regard to the performance of the standard and composite ab initio procedures, we draw the following conclusions:

$>$ The CRBH20 dataset proves to be a challenging test for nearly all of the standard and composite $\mathrm{ab}$ initio procedures.

$>$ The composite Gn-type procedures show moderate performance with RMSDs ranging between 4.9 (G4(MP2)-6X) and 12.6 (G3(MP2)B3) kJ mol ${ }^{1}$.

$>$ The composite CBS-QB3 and CBS-APNO procedures show significantly better performance with RMSDs of 3.1 and $1.5 \mathrm{~kJ} \mathrm{~mol}^{1}$, respectively.

With the exception of one method (see next bullet point), all the standard and modified MPn-based methods (MP2, MP2.5, MP3, MP3.5, MP4, SCS-MP2, and SCS-MP3) show poor performance with RMSDs ranging between 5.7 (MP4(SDQ)) and 29.5 (MP3) kJ mol ${ }^{1}$. 
$>$ The newly defined MP4av procedure - an average of MP4(SDQ) and MP4(SDTQ) - gives excellent performance with an RMSD of merely $2.1 \mathrm{~kJ}$ mol ${ }^{1}$. This procedure also performs well for the 26 barrier heights of pericyclic reactions in the BHPERI subset of the GMTKN30 database (with RMSD $=2.5 \mathrm{~kJ} \mathrm{~mol}^{-1}$ ). ${ }^{6}$

$>$ The $\operatorname{CCSD}(\mathrm{T})$ method in conjunction with the $\mathrm{A}^{\prime} \mathrm{VDZ}$ and $\mathrm{A}^{\prime} \mathrm{VTZ}$ basis sets performs poorly with RMSDs of 13.9 and $5.0 \mathrm{~kJ} \mathrm{~mol}^{-1}$, respectively.

Estimating the CCSD(T)/CBS energy from the CCSD(T)/A'VDZ energy and adding an MP2-based basis-set-correction term results in an RMSD of only $1.7 \mathrm{~kJ} \mathrm{~mol}^{-1}$. This simple and cost-effective procedure outperforms all of the considered ab initio and composite procedures (with the exception of CBS-APNO).

\section{Appendix A. Supplementary data}

Diagnostics indicating the importance of post-CCSD(T) contributions for the species involved in the CRBH20 database (Table S1); selected bond lengths of bonds that are being broken and formed in the transition structures in the CRBH20 database (Table S2); statistical analysis for the performance of DFT and DHDFT procedures for the calculation of the reaction barrier heights of the CRBH20 database in the reverse direction, i.e., for cycloaddition reactions (Table S3); overview of the basis set convergence of conventional DFT methods (Table S4); overview of the basis set convergence of the standard and modified ab initio procedures (Table S5); and full references for Ref. 18 (Molpro 2012), Ref. 29 (Gaussian 09), and Ref. 74 (ORCA). For the convenience of the reader the Supplementary data also includes a directory (CRBH20_input_files_and_script.zip) with the Gaussian 09 input files for the species involved in the CRBH20 database and a perl script that calculates the reaction barrier heights and the error statistics from our W1-F12 and W1w reference values. Supplementary data associated with this article can be found, in the online version, at http://dx.doi.org/10.1016/j.chemphys.2015.xx.xxx.

\section{Acknowledgments}

Dedicated to the lifetime achievements and memory of Professor Tom Ziegler. This research was undertaken with the assistance of resources from the National Computational Infrastructure (NCI), which is supported by the Australian Government. We gratefully acknowledge the system administration support provided by the Faculty of Science at UWA to the Linux cluster of the Karton group, the provision of an Australian Postgraduate Award (to L-J.Y.), and an Australian Research Council (ARC) Discovery Early Career Researcher Award (to A.K., project number: DE140100311). 


\section{References}

${ }^{1}$ A. E. Mattsson, Science 298 (2002) 759.

${ }^{2}$ R. Peverati, D. G. Truhlar, Phil. Trans. R. Soc. A 372 (2013) 20120476.

${ }^{3}$ L. Goerigk, S. Grimme, J. Chem. Theory Comput. 7 (2011) 291.

${ }^{4}$ A. Karton, S. Daon, J. M. L. Martin, Chem. Phys. Lett. 510 (2011) 165.

${ }^{5}$ L. Goerigk, A. Karton, J. M. L. Martin, L. Radom Phys. Chem. Chem. Phys. 15 (2013) 7028.

${ }^{6}$ A. Karton, L. Goerigk, J. Comp. Chem. 36 (2015) 622.

${ }^{7}$ V. Guner, K. S.Khuong, A. G. Leach, P. S. Lee, M. D. Bartberger, K. N. Houk, J. Chem. Phys. A 107 (2003) 11445.

${ }^{8}$ D. H. Ess, K. N. Houk, J. Phys. Chem. A 109 (2005) 9542.

${ }^{9}$ T. C. Dinadayalane, R. Vijaya, A. Smitha, G. N. Sastry, J. Phys. Chem. A 106 (2002) 1627.

${ }^{10}$ L. Goerigk, S. Grimme, J. Chem. Theory Comput. 7 (2011) 291.

${ }^{11}$ A. Karton, J. M. L. Martin, J. Chem. Phys. 136 (2012) 124114.

${ }^{12}$ L. A. Curtiss, P. C. Redfern, K. Raghavachari, J. Chem. Phys. 126 (2007) 084108.

${ }^{13}$ L. A. Curtiss, P. C. Redfern, K. Raghavachari, J. Chem. Phys. 127 (2007) 124105.

${ }^{14}$ J. A. Montgomery Jr, M. J. Frisch, J. W. Ochterski, G. A. Petersson, J. Chem. Phys. 110 (1999) 2822; ibid 112 (2000) 6532.

${ }^{15}$ J. W. Ochterski, G. A. Petersson, J. A. Montgomery Jr, J. Chem. Phys. 104 (1996) 2598.

${ }^{16}$ J. M. L. Martin, G. Oliveira, J. Chem. Phys. 111 (1999) 1843.

${ }^{17}$ A. Karton, E. Rabinovich, J. M. L. Martin, B. Ruscic, J. Chem. Phys. 125 (2006) 144108.

${ }^{18}$ MOLPRO is a package of ab initio programs written by H.-J. Werner, P. J. Knowles, G. Knizia, F. R. Manby, M. Schütz, P. Celani, T. Korona, R. Lindh, A. Mitrushenkov, G. Rauhut, et al. See: http:www.molpro.net.

${ }^{19}$ H.-J. Werner, P. J. Knowles, G. Knizia, F. R. Manby, M. Schütz, WIREs Comput. Mol. Sci. 2 (2012) 242 .

${ }^{20}$ K. A. Peterson, D. Feller, D. A. Dixon, Theor. Chem. Acc. 131 (2012) 1079.

${ }^{21}$ T. Helgaker, W. Klopper, D. P. Tew, Mol. Phys. 106 (2008) 2107.

${ }^{22}$ T. H. Dunning, J. Chem. Phys. 90 (1989) 1007.

${ }^{23}$ R. A. Kendall, T. H. Dunning, Jr., R. J. Harrison, J. Chem. Phys. 96 (1992) 6796.

${ }^{24}$ T. H. Dunning, K. A. Peterson, A. K. Wilson, J. Chem. Phys. 114 (2001) 9244.

${ }^{25}$ A. Karton, Chem. Phys. Lett. 585 (2014) 330.

${ }^{26}$ C. Lee, W. Yang, R. G. Parr, Phys. Rev. B 37 (1988) 785.

${ }^{27}$ A. D. Becke, J. Chem. Phys. 98 (1993) 5648. 
${ }^{28}$ P. J. Stephens, F. J. Devlin, C. F. Chabalowski, M. J. Frisch, J. Phys. Chem. 98 (1994) 11623.

${ }^{29}$ M. J. Frisch, G. W. Trucks, H. B. Schlegel, G. E. Scuseria, M. A. Robb, J. R. Cheeseman, G. Scalmani, V. Barone, B. Mennucci, G. A. Petersson, et al. Gaussian 09, Revision D.01; Gaussian, Inc.: Wallingford CT, 2009.

${ }^{30}$ J. P. Perdew, K. Schmidt, AIP Conf. Proc. 577 (2001) 1.

${ }^{31}$ A. D. Becke, Phys. Rev. A 38 (1988) 3098.

${ }^{32}$ S. Grimme, J. Comp. Chem. 27 (2006) 1787.

${ }^{33}$ A. D. Boese, N. C. Handy, J. Chem. Phys. 114 (2001) 5497.

${ }^{34}$ J. P. Perdew, K. Burke, M. Ernzerhof, Phys. Rev. Lett. 77 (1996) 3865; ibid Phys. Rev. Lett. 78 (1997) 1396.

${ }^{35}$ J. P. Perdew, Phys. Rev. B 33 (1986) 8822.

${ }^{36}$ J. P. Perdew, J. A. Chevary, S. H. Vosko, K. A. Jackson, M. R. Pederson, D. J. Singh, C. Fiolhais, Phys. Rev. B 46 (1992) 6671.

${ }^{37}$ R. Peverati, Y. Zhao and D. G. Truhlar, J. Phys. Chem. Lett. 2 (2011) 1991.

${ }^{38}$ R. Peverati, D. G. Truhlar, J. Chem. Theory and Comput. 8 (2012) 2310.

${ }^{39}$ Y. Zhao, D. G. Truhlar, J. Chem. Phys. 125 (2006) 194101.

${ }^{40}$ J. M. Tao, J. P. Perdew, V. N. Staroverov, G. E. Scuseria, Phys. Rev. Lett. 91 (2003) 146401.

${ }^{41}$ A. D. Boese, N. C. Handy, J. Chem. Phys. 116 (2002) 9559.

${ }^{42}$ T. van Voorhis, G. E. Scuseria, J. Chem. Phys. 109 (1998) 400.

${ }^{43}$ A. D. Becke, J. Chem. Phys. 104 (1996) 1040.

${ }^{44}$ R. Peverati, D. G. Truhlar, J. Phys. Chem. Lett. 3 (2012) 117.

${ }^{45}$ R. Peverati, D. G. Truhlar, Phys. Chem. Chem. Phys. 10 (2012) 13171.

${ }^{46}$ A. D. Becke, J. Chem. Phys. 98 (1993) 1372.

${ }^{47}$ C. Adamo, V. Barone, J. Chem. Phys. 110 (1999) 6158.

${ }^{48}$ F. A. Hamprecht, A. J. Cohen, D. J. Tozer, N. C. Handy, J. Chem. Phys. 109 (1998) 6264.

${ }^{49}$ H. L. Schmider, A. D. Becke, J. Chem. Phys. 108 (1998) 9624.

${ }^{50}$ X. Xu, Q. Zhang, R. P. Muller, W. A. Goddard, J. Chem. Phys. 122 (2005) 014105.

${ }^{51}$ R. Peverati, D. G. Truhlar, J. Chem. Phys. 135 (2011) 191102

${ }^{52}$ Y. Zhao, N. E. Schultz, D. G. Truhlar, J. Chem. Phys. 123 (2005) 161103.

${ }^{53}$ Y. Zhao, N. E. Schultz, D. G. Truhlar, J. Chem. Theory and Comput. 2 (2006) 364.

${ }^{54}$ Y. Zhao, D. G. Truhlar, Theor. Chem. Acc. 120 (2008) 215.

${ }^{55}$ A. D. Boese, J. M. L. Martin, J. Chem. Phys. 121 (2004) 3405. 
${ }^{56}$ V. N. Staroverov, G. E. Scuseria, J. Tao, J. P. Perdew, J. Chem. Phys. 119 (2003) 12129.

${ }^{57}$ Y. Zhao, D. G. Truhlar, J. Phys. Chem. A 109 (2005) 5656.

${ }^{58}$ L. Goerigk, S. Grimme, WIREs Comput. Mol. Sci. 4 (2014) 576.

${ }^{59}$ S. Grimme, J. Chem. Phys. 124 (2006) 034108.

${ }^{60}$ A. Karton, A. Tarnopolsky, J.-F. Lamere, G. C. Schatz, J. M. L. Martin, J. Phys. Chem. A 112 (2008) 12868.

${ }^{61}$ A. Tarnopolsky, A. Karton, R. Sertchook, D. Vuzman, J. M. L. Martin, J. Phys. Chem. A 112 (2008) 3.

${ }^{62}$ S. Kozuch, D. Gruzman, J. M. L. Martin, J. Phys. Chem. C 114 (2010) 20801.

${ }^{63}$ S. Kozuch, J. M. L. Martin, Phys. Chem. Chem. Phys. 13 (2011) 20104.

${ }^{64}$ S. Kozuch, J. M. L. J. Martin, Comp. Chem. 34 (2013) 2327.

${ }^{65}$ T. Yanai, D. Tew, N. Handy, Chem. Phys. Lett. 393 (2004) 51.

${ }^{66}$ O. A. Vydrov, G. E. Scuseria, J. Chem. Phys. 125 (2006) 34109.

${ }^{67}$ J.-D. Chai, M. Head-Gordon, J. Chem. Phys. 128 (2008) 084106.

${ }^{68}$ J.-D. Chai, M. Head-Gordon, Phys. Chem. Chem. Phys. 10 (2008) 6615.

${ }^{69}$ R. Peverati, D. G. Truhlar, J. Phys. Chem. Lett. 2 (2011) 2810.

${ }^{70}$ S. Grimme, S. Ehrlich, L. Goerigk, J. Comput. Chem. 32 (2011) 1456.

${ }^{71}$ S. Grimme, J. Antony, S. Ehrlich and H. Krieg, J. Chem. Phys. 132 (2010) 154104.

${ }^{72}$ S. Grimme, WIREs Comput. Mol. Sci. 1 (2011) 211.

${ }^{73}$ A. D. Becke, E. R. Johnson, J. Chem. Phys. 123 (2005) 154101.

74 ORCA is a modern electronic structure program package written by F. Neese, with contributions from Ute Becker, Dmytro Bykov, Dmitry Ganyushin, Andreas Hansen, Robert Izsak, Dimitrios G. Liakos, Christian Kollmar, Simone Kossmann, Dimitrios A. Pantazis, Taras Petrenko, et al. Max Planck Institute for Chemical Energy Conversion, 2014.

${ }^{75}$ F. Neese, WIREs Comput. Mol. Sci. 2 (2012) 73.

${ }^{76}$ B. Chan, J. Deng, L. Radom, J. Chem. Theory Comput. 7 (2011) 112.

${ }^{77}$ S. Grimme, J. Chem. Phys. 118 (2003) 9095.

${ }^{78}$ M. Pitonak, P. Neogrady, J. Cerny, S. Grimme, P. Hobza, Chem. Phys. Chem. 10 (2009) 282.

${ }^{79}$ S. Grimme, J. Comput. Chem. 24 (2003) 1529.

${ }^{80}$ T. Takatani, E. E. Hohenstein, C. D. Sherrill, J. Chem. Phys. 128 (2008) 124111.

${ }^{81}$ M. Pitonak, J. Rezac and P. Hobza, Phys. Chem. Chem. Phys. 12 (2011) 9611.

${ }^{82}$ B. A. Burkett, J. M. Kane-Barber, R. J. O’Reilly, L. Shi, Tetrahedron Lett. 48 (2007) 5355. 
${ }^{83}$ R. J. O’Reilly, L. Radom, Org. Lett. 11 (2009) 1325.

${ }^{84}$ J. N. Kim, K. S. Jung, H. J. Lee, J. S. Son, Tetrahedron Lett. 38 (1997) 1596.

${ }^{85}$ K. S. Jung, J. L. Hong, H. N. Song, J. N. Kim, Synth. Commun. 28 (1998) 1879.

${ }^{86}$ J. N. Kim, H. J. Song, E. K. Ryu, Synth. Commun. 24 (1994) 1101.

${ }^{87}$ K. Tomonori, E. Shoji, S. J. Tadashi, Chem. Soc., Perkin Trans 111 (1984) 2641.

${ }^{88}$ A. Karton, J. M. L. Martin, J. Chem. Phys. 133 (2010) 144102.

${ }^{89}$ A. Karton, I. Kaminker, J. M. L. Martin, J. Phys. Chem. A 113 (2009) 7610.

${ }^{90}$ J. Baker, M. Muir, J. Audzelm and A. Scheimner, ACS Symp. Ser. 629 (1996) 342.

${ }^{91}$ Jensen, F. Introduction to Computational Chemistry; Wiley: Chichester, UK, 1999.

${ }^{92}$ Cramer, C. J. Essentials of Computational Chemistry; Wiley: New York, NY, 2002.

${ }^{93}$ S. E. Wheeler, D. H. Ess, K. N. Houk, J. Phys. Chem. A 112 (2008) 1798.

${ }^{94}$ A. Halkier, T. Helgaker, P. Jørgensen, W. Klopper, H. Koch, J. Olsen, A. K. Wilson, Chem. Phys. Lett. 286 (1998) 243.

${ }^{95}$ P. Jurecka, J. Sponer, J. Cerny, P. Hobza, Phys. Chem. Chem. Phys. 8 (2006) 1985.

${ }^{96}$ D. G. Liakos, F. Neese, J. Phys. Chem. A 116 (2012) 4801.

${ }^{97}$ B. Brauer, M. K. Kesharwani, J. M. L. Martin, J. Chem. Theory Comput. 10 (2014) 3791.

${ }^{98}$ P. Jure ka, P. Hobza, Chem. Phys. Lett. 365 (2002) 89.

${ }^{99}$ L.-J. Yu, A. Karton, Chem. Phys. 441 (2014) 166.

${ }^{100}$ L.-J. Yu, F. Sarrami, A. Karton, R. J. O’Reilly, Mol. Phys. 113 (2015) 1284.

${ }^{101}$ X. He, L. Fusti-Molnar, and K. M. Merz, Jr., J. Phys. Chem. A 113 (2009) 10096. 
Graphical TOC

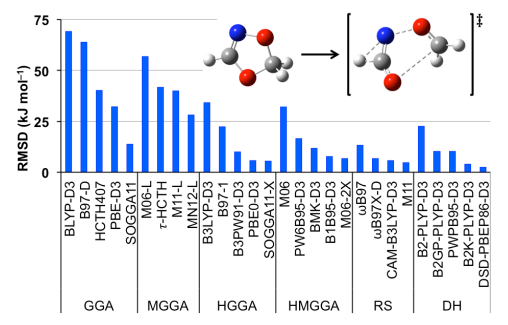

